\title{
Prognostic value of Ki-67 for prostate cancer death in a conservatively managed cohort
}

\author{
G Fisher ${ }^{1}$, Z H Yang ${ }^{1}$, S Kudahetti ${ }^{2}$, H Møller ${ }^{3}$, P Scardino ${ }^{4}$, J Cuzick ${ }^{1}$, D M Berney ${ }^{\star 2}$ and on behalf of the \\ Transatlantic Prostate Group \\ ${ }^{1}$ Centre for Cancer Prevention, Wolfson Institute of Preventive Medicine, Queen Mary University of London, London EC1M 6BQ, \\ UK; ${ }^{2}$ Department of Molecular Oncology, Barts Cancer Centre, Barts and the London, School of Medicine and Dentistry, Queen \\ Mary University of London, Charterhouse Square, London, EC1M 6BQ, UK; ${ }^{3}$ King's College London, Thames Cancer Registry, \\ London, UK and ${ }^{4}$ Department of Urology, Memorial Sloan-Kettering Cancer Center, New York, NY, USA
}

Background: Standard clinical parameters cannot accurately differentiate indolent from aggressive prostate cancer. Our previous work showed that immunohistochemical (IHC) Ki-67 improved prediction of prostate cancer death in a cohort of conservatively treated clinically localised prostate cancers diagnosed by transurethral resection of the prostate (TURP). Here, we present results in a more clinically relevant needle biopsy cohort.

Methods: Biopsy specimens were microarrayed. The percentage of Ki-67 positively stained malignant cells per core was measured and the maximum score per individual used in analysis of time to death from prostate cancer using a Cox proportional hazards model.

Results: In univariate analysis $(n=293)$, the hazard ratio (HR) (95\% confidence intervals) for dichotomous Ki-67 ( $\leqslant 10 \%,>10 \%)$ was $3.42(1.76,6.62) \chi^{2}(1 \mathrm{df})=9.8, P=0.002$. In multivariate analysis, Ki-67 added significant predictive information to that provided by Gleason score and prostate-specific antigen $\left(H R=2.78(1.42,5.46), \chi^{2}(1 \mathrm{df})=7.0, P=0.008\right)$.

Conclusion: The IHC Ki-67 scoring on prostate needle biopsies is practicable and yielded significant prognostic information. It was less informative than in the previous TURP cohort where tumour samples were larger and more comprehensive, but in more contemporary cohorts with larger numbers of biopsies per patient, Ki-67 may prove a more powerful biomarker.

The optimal treatment for organ confined prostate cancer remains a challenge for health professionals worldwide. While potentially curative treatments exist, they are associated with substantial morbidity and the five-fold difference between prostate cancer incidence and mortality in many developed countries indicates that there is substantial over treatment of indolent neoplasms (Etzioni et al, 2002). As serum prostate-specific antigen (PSA) testing becomes more common, the incidence of prostate cancer will continue to rise further, and a greater proportion of tumours will be indolent and potentially manageable by active surveillance.

The differentiation of indolent from aggressive prostate cancer was recently ranked top priority for research, by a consultation conducted by the James Lind Alliance (Lophatananon et al, 2011).
Management of the disease relies largely on standard clinical factors including Gleason score, PSA level, clinical stage and measures of tumour extent on biopsy and imaging, but these are clearly inadequate and better markers of prognosis are needed.

Molecular biomarkers in tissue, urine, or serum have proven difficult to validate. Many biomarkers have shown association with Gleason score and some have also been associated with outcome after radical treatment (D'Amico et al, 2008; Vergis et al, 2010; Kristiansen, 2012), but comparatively little work has been done on cohorts of prostate cancer managed conservatively, especially when the diagnosis was made by a needle biopsy where tissue is limited.

The most promising immunohistochemical (IHC) biomarker identified so far is Ki-67, a marker of cell proliferation. As the 
grading system in prostate cancer (unlike many other cancers) does not consider the proliferation rate of the cells, it is possible that measuring the cell proliferation rate in prostate tumours could yield additional prognostic information. Ki-67 (1\% cutoff) was shown to be useful in predicting time to radical treatment, in a biopsy tissue microarray study of 60 patients on active surveillance (Jhavar et al, 2009) and a range of studies in cohorts with larger radical prostatectomy (RP) or transurethral resection of the prostate (TURP) diagnostic samples, reviewed by Kristiansen (2012), have shown that Ki-67 IHC measurements can significantly predict prostate cancer outcome. There has been little consensus in the choice of Ki-67 cutoff points, and predictions of progression, in terms of biochemical recurrence following radical treatments, have been based on a wide range from $2.4 \%$ to $26 \%$, while a range from $3 \%$ to $10.3 \%$ has shown the prognostic significance of Ki-67 in both overall and disease-specific survival. Detailed results are provided in Supplementary Table 1. There is evidence in the existing literature (Stattin et al, 1997; Cowen et al, 2002; Rubin et al, 2002; Sebo et al, 2002; Pollack et al, 2003; Li et al, 2004; Pollack et al, 2004; Rubio et al, 2005; Gunia et al, 2008; Laitinen, 2008; Berney et al, 2009; Khor et al, 2009; Zellweger et al, 2009) that Ki-67 can improve predictions of prostate cancer outcome based on standard factors alone, in men treated conservatively or radically. Multivariate HRs for prostate cancerspecific survival and prostate cancer recurrence are shown in Figure $1 \mathrm{~A}$ and $\mathrm{B}$, respectively, and additional information is summarised in Table 1.
Although molecular mRNA markers of cell proliferation gene expression (Cuzick et al, 2012) have shown promise, they are more technically demanding and expensive to perform.

Our previous work, on the Trans Atlantic Prostate Group cohort of conservatively managed prostate cancers diagnosed by TURP showed that Ki-67 was an independent prognostically significant marker when PSA, Gleason score, and tumour extent were also considered (Berney et al, 2009). However, since TURP is no longer a common means of diagnosis of prostate cancer, any practicable test would need to be useful on needle biopsy specimens. Here, we report results of such an investigation.

\section{MATERIALS AND METHODS}

Patients. Potential cases of prostate cancer were identified from six cancer registries in Great Britain. Case notes from collaborating hospitals were reviewed, and full details of these patients have been previously reported (Cuzick et al, 2006). Men were included in this study if they had clinically localised prostate cancer, diagnosed by use of needle biopsy between 1990 and 1996 (inclusively), were younger than 76 years at the time of diagnosis, and had a baseline PSA measurement. Patients with PSA values greater than $100 \mathrm{ng} \mathrm{ml}^{-1}$ were excluded as likely to have metastatic disease. Patients treated with RP or radiation therapy, or who died or showed evidence of metastatic disease within 6 months of

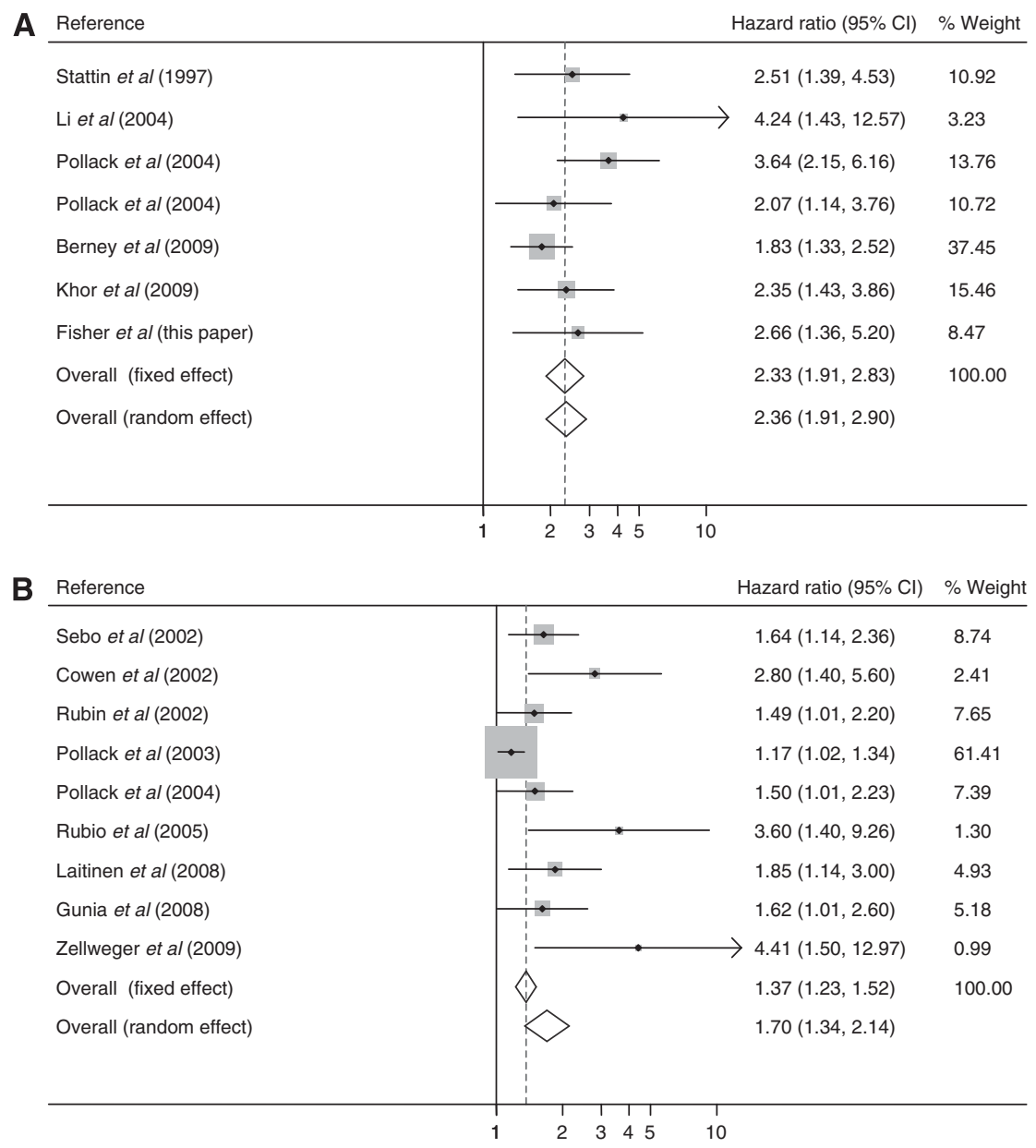

Figure 1. Hazard ratio for Ki-67 in multivariate analysis after adjustment for covariates, in the existing literature, for (A) prostate cancer-specific survival (I-squared $=7.5 \%, P=0.371)$ and $(B)$ prostate cancer recurrence $(\mathrm{I}$-squared $=61.9 \%, P=0.007)$. The area of the box is proportional to the amount of information available, and the horizontal bars represent $95 \%$ confidence intervals. 
Table 1. Published reports of the prognostic value of Ki-67 in multivariate analyses with Hazard ratio's (HR) after adjustment for covariates

\begin{tabular}{|c|c|c|c|c|c|c|c|}
\hline Reference & End point & Cohort type & Cohort size & Cutoff (\%) & $\boldsymbol{P}$-value & HR (95\% Cls) & Covariates \\
\hline Stattin et al (1997) & PCS & TURP, WW & 125 & 3 & 0.0023 & $2.51(1.39,4.53)$ & G TA \\
\hline Li et al (2004) & PCS & RX & 108 & 3.5 & 0.009 & $4.24(1.43,12.57)$ & G T Tx \\
\hline Pollack et al (2004) & PCS & RX & 496 & CONT & 0.0001 & $3.64(2.15,6.16)$ & G TP Tx \\
\hline Pollack et al (2004) & PCS & RX & 496 & 7.1 & 0.0174 & $2.07(1.14,3.76)$ & G TP Tx \\
\hline Berney et al (2009) & PCS & TURP, WW & 685 & 5 & 0.0003 & $1.83(1.33,2.53)$ & G P Px \\
\hline Khor et al (2009) & PCS & RX & 637 & 11.3 & 0.0007 & $2.35(1.43,3.85)$ & G TA Tx \\
\hline Fisher et al (this paper) & PCS & BX, WW & 293 & 10 & 0.011 & $2.66(1.36,5.2)$ & G P \\
\hline Sebo et al (2002) & PCR & $\mathrm{RP}$ & 454 & CONT & 0.008 & $1.64(1.14,2.36)$ & G Px \\
\hline Cowen et al (2002) & PCR & $\mathrm{RX}$ & 106 & 3.5 & 0.003 & $2.8(1.4,5.4)$ & GP T \\
\hline Rubin et al (2002) & PCR & $\mathrm{RP}$ & 88 & CONT & 0.047 & $1.49(1.01,2.2)$ & G P Px \\
\hline Pollack et al (2003) & PCR & RX & 64 & CONT & 0.04 & $1.17(1.02,1.35)$ & G P T bax/bcl-2 \\
\hline Pollack et al (2004) & PCR & RX & 496 & CONT & 0.045 & $1.5(1.01,2.23)$ & GP T Tx \\
\hline Rubio et al (2005) & PCR & $\mathrm{RP}$ & 91 & 5 & 0.006 & $3.6(1.4,8.9)$ & G \\
\hline Laitinen et al (2008) & PCR & $\mathrm{RP}$ & 181 & 16 & 0.013 & $1.85(1.14,3.01)$ & G P T EZH2 MCM7 \\
\hline Gunia et al (2008) & PCR & $\mathrm{RP}$ & 528 & 5 & 0.048 & $1.62(1.01,2.61)$ & G P T Px \\
\hline Zellweger et al (2009) & PCR & $\mathrm{BX}, \mathrm{RP}$ & 279 & 10 & 0.008 & $4.41(1.5,13.2)$ & G \\
\hline
\end{tabular}

diagnosis were also excluded, as were men who had hormone therapy before the diagnostic biopsy.

Original histological specimens from the diagnostic procedure were requested, collected, and centrally reviewed by a panel of expert urological pathologists to confirm the diagnosis and to reassign Gleason scores by use of a contemporary and consistent interpretation of the Gleason scoring system (Epstein et al, 2005). Follow-up was through the cancer registries and the last update of vital status took place in December 2009. Deaths were divided into those from prostate cancer and those from other causes, according to WHO standardised criteria (WHO, 2010). National ethics approval was obtained from the Northern Multicentre Research Ethics Committee, followed by local ethics committee approval at each of the collaborating hospitals.

Ki-67 immunohistochemistry. Diagnostic formalin-fixed paraffin-embedded (FFPE) needle biopsy tissue blocks and slides (where available) were requested. Areas of cancer were marked and those with adequate tumour tissue available were microarrayed, by excising the tumour tissue with spaced blades and positioning it in a preformed donor block, as given in detail elsewhere (McCarthy et al, 2011).

Tissue microarray (TMA) sections were immunoassayed for Ki-67 using MIB-1 antibody, DAKO, Carpinteria, CA, USA, as detailed previously (Berney et al, 2009). Briefly, cells were scored in a semiquantitative manner, by an expert prostatic pathologist with normal tonsil as a positive control, and the percentage of positive cells was estimated as the proportion of Ki-67 stained malignant cells, in a manner similar to that used in routine pathology departments for the assessment of proliferation index in other organs. All nuclear immunostaining was recorded as positive and was clearly either strongly positive or negative. Where multiple cancer cores per patient were stained, the maximum value percentage staining (Ki-67 score) was used for analysis. These were practical decisions to make the technique robust for any pathology laboratory with experience in immunohistochemistry and allow results to be directly comparable to our previous work.
Statistical analysis. The primary end point was time to death from prostate cancer, which was analysed using a Cox proportional hazards model. Observations were censored on the date of last followup, or at death from other causes. Covariates included centrally reviewed Gleason score, baseline PSA value, clinical stage, extent of cancer (proportion of positive cores), age at diagnosis, and Ki-67.

The PSA concentration was modelled as the natural logarithm of $\left(1+\right.$ PSA $\left.\left(\mathrm{ng} \mathrm{ml}^{-1}\right)\right)$, Ki-67 as a dichotomous variable $(\leqslant 10 \%$, $>10 \%$ ) and Gleason scores were grouped into $<7,=7$, and $>7$, for the primary analysis. We combined Gleason $3+4$ and $4+3$, because they showed little difference in our previous analysis (Cuzick et al, 2006).

All $P$-values were two-sided and 95\% CIs and $P$-values, obtained from partial likelihoods of proportional hazards models, were based on $\chi^{2}$ statistics with 1 degree of freedom, unless otherwise indicated. The main assessment was a univariate analysis of the association between death from prostate cancer and Ki-67 score. A multivariate Cox proportional hazards model was used to measure the added prognostic information after adjustment for the baseline variables. This was measured as the decrease in the likelihood ratio $\chi^{2}$ when the Ki-67 score was omitted from a model containing it and the other relevant baseline clinical and pathological variables. Statistical analyses were done with STATA (version 11.2, StataCorp, College Station, TX, USA).

\section{RESULTS}

The derivation of the cohort is shown in Figure 2 and 293 men were available for analysis. The mean age at diagnosis was 69.6 years and during follow-up (mean 9.03 years; maximum 19.4 years), 217 (74\%) men had died, 91 of prostate cancer, corresponding to $31 \%$ of the total cohort.

A total of 339 cores, from 293 patients, comprising one $(n=258$ $(88 \%))$ to three $(n=7(2 \%))$ per patient, were stained for Ki-67. The maximum percent of cancerous cells staining per patient was evaluated; $106(36 \%)$ scored as $1 \%, 87(30 \%)$ as $5 \%, 31(11 \%)$ as 
$10 \%, 16(5 \%)$ as $>10 \%$, and $53(18 \%)$ as 0 (Figure 3 ), and the mean Ki-76 score was $3.99 \%$. Ki-67 score was significantly correlated with Gleason score, but not PSA or initial treatment (Table 2).

Ki-67 score was analysed as a binary variable for its prognostic value as a biomarker for prostate cancer-specific survival.

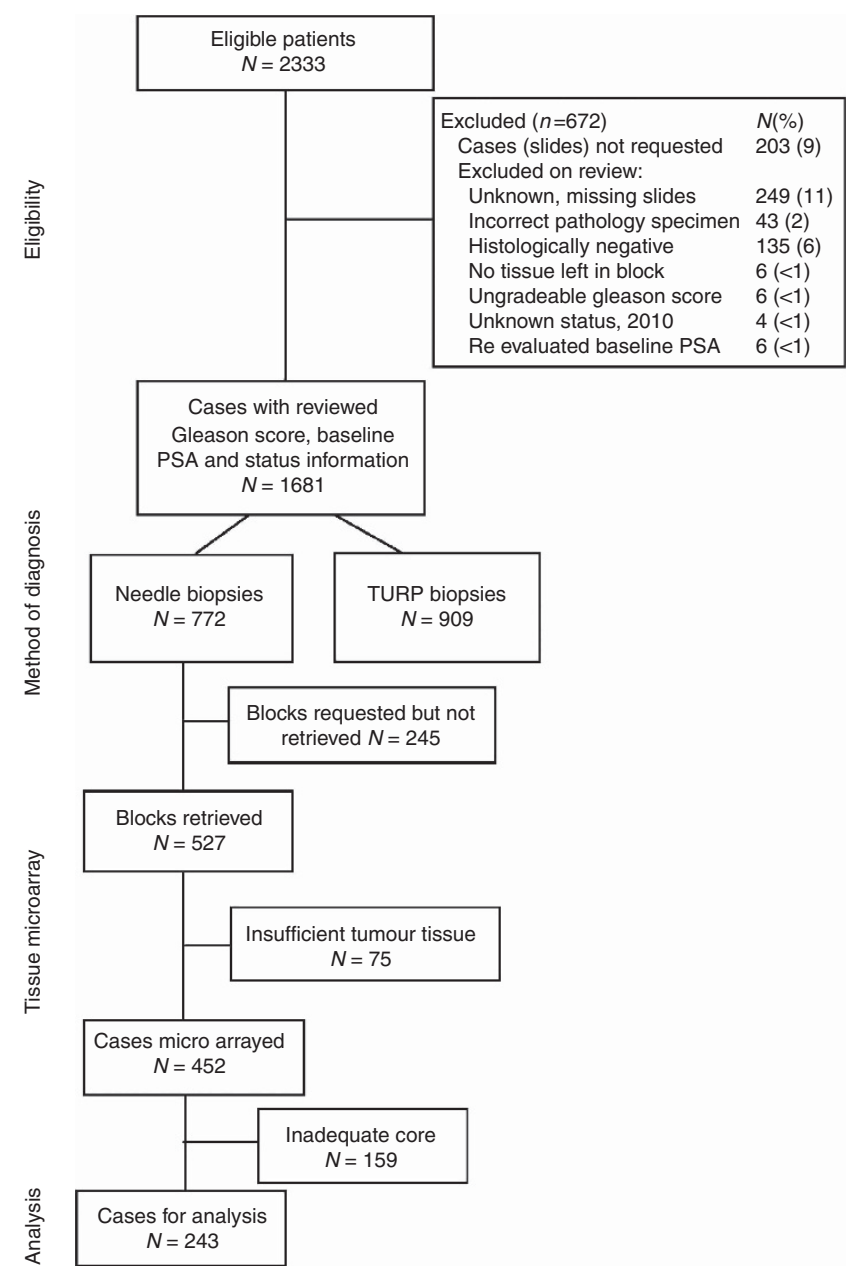

Figure 2. Consort diagram: overview of cohort.

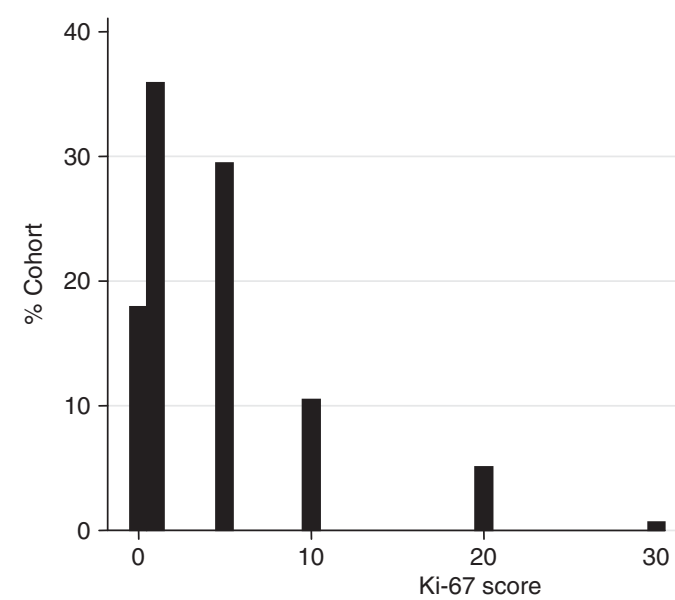

Figure 3. Distribution of $\mathrm{Ki}-67$ score, in diagnostic needle biopsy tissue from a conservatively managed cohort of 293 men.
In univariate analysis, Gleason score, PSA, extent of disease, age at diagnosis, and Ki-67 score were all significant predictors of prostate cancer death (Table 3). Kaplan-Meier survival curves for Ki-67 in three groups (Figure 4) showed little difference between the two highest survival groups ( $\leqslant 5 \%$ and $>5$ to $\leqslant 10 \%$ ) and these were combined to form a dichotomous variable with a cutoff of $\leqslant 10 \%$ which gave an $\mathrm{HR}=3.42(1.76,6.62), \chi^{2}(1 \mathrm{df})=9.8$, $P=0.002$. The majority of deaths (81) and the corresponding 277 cases were in the low Ki-67 groups with 10 deaths (16 cases) belonging to those with a high level Ki-67 score (>10\%) (Table 3). We also assessed $\mathrm{Ki}-67$ as a continuous variable (log scale) and as a dichotomous variable with $5 \%$ cutoff point, but results were similar.

In multivariate analysis, the dichotomous Ki-67 variable $(\leqslant 10 \%,>10 \%)$ added significant predictive information to that provided by Gleason score and PSA alone $(\mathrm{HR}=2.78(1.42,5.46)$, $\left.\chi^{2}(1 \mathrm{df})=7.0, P=0.008\right)$ (Table 3$)$. Covariates extent of disease and age were much less informative and excluded from the final model as they did not add significant predictive value. In clinical subgroups based on Gleason score or PSA, no heterogeneity was seen (Figure 5).

\section{DISCUSSION}

Although Ki-67 is the most studied of any immunochemical biomarker in prostate cancer, to our knowledge this is the first study to assess $\mathrm{Ki}-67$ in conjunction with other known prognostic factors in a needle biopsy cohort of conservatively managed prostate cancers, with long-term survival data. Evidence from a large number of other studies shows that it is an independent significant prognostic marker in multivariate analysis of prostate cancer progression and death, but this is primarily in cohorts of patients treated by radical therapies.

This study shows that Ki-67 remains an important prognostic factor in multivariate analysis in a needle biopsy cohort, and can improve predictions of disease-specific survival based on Gleason score and PSA alone. There was no evidence for heterogeneity according to Gleason score or PSA, but results were not as strong as those seen previously in the TURP cohort (Berney et al, 2009). There may be several reasons for this. Prostate cancer is a

Table 2. Cross-tabulation of Ki-67 staining (\% cells) with Gleason score and baseline PSA level $(n=293)$

\begin{tabular}{|c|c|c|c|c|c|c|c|}
\hline \multirow[t]{2}{*}{ Variable } & \multicolumn{5}{|c|}{ Ki-67 } & & \multirow[t]{2}{*}{$\begin{array}{c}\text { Correlation } \chi^{2} \\
(\boldsymbol{P} \text {-value })\end{array}$} \\
\hline & 0 & 1 & 5 & 10 & $20+$ & Total & \\
\hline \multicolumn{7}{|c|}{ Gleason score } & $31.6(<0.001)$ \\
\hline$<7$ & 17 & 44 & 17 & 5 & 1 & 84 & \\
\hline 7 & 23 & 44 & 45 & 17 & 4 & 133 & \\
\hline$>7$ & 13 & 18 & 25 & 9 & 11 & 76 & \\
\hline \multicolumn{7}{|c|}{ Baseline PSA (ng ml ${ }^{-1}$ ) } & $8.87(0.92)$ \\
\hline$\leqslant 4$ & 2 & 4 & 1 & 1 & 0 & 8 & \\
\hline$>4-10$ & 9 & 24 & 12 & 3 & 2 & 50 & \\
\hline$>10-25$ & 19 & 38 & 33 & 14 & 6 & 110 & \\
\hline$>25-50$ & 13 & 23 & 24 & 7 & 3 & 70 & \\
\hline$>50-100$ & 10 & 17 & 17 & 6 & 5 & 55 & \\
\hline Total & 53 & 106 & 87 & 31 & 16 & 293 & \\
\hline
\end{tabular}


Table 3. Univariate and multivariate analysis for time to death from prostate cancer in a conservatively managed needle biopsy cohort ( $n=293$ )

\begin{tabular}{|c|c|c|c|}
\hline & & Univariate & Multivariate (G, PSA, Ki-67) \\
\hline Variable & $D / N$ & Hazard ratio $(95 \% \mathrm{Cl})$ & Hazard ratio $(95 \% \mathrm{Cl})$ \\
\hline \multicolumn{4}{|c|}{ Gleason score } \\
\hline $\begin{array}{l}<7 \\
7 \\
>7\end{array}$ & $\begin{array}{c}15 / 84 \\
44 / 133 \\
32 / 76\end{array}$ & $\begin{array}{c}1(\mathrm{ref}) \\
2.35(1.30,4.22) \\
4.57(2.46,8.48) \\
\chi^{2}=25.5(P<0.001)^{\mathrm{a}}\end{array}$ & $\begin{array}{c}1(\mathrm{ref}) \\
1.96(1.08,3.55) \\
3.20(1.69,6.07) \\
\chi^{2}=13.7(P<0.0001)\end{array}$ \\
\hline \multicolumn{4}{|c|}{ PSA $\left(\log (1+P S A)\left(n g \mathrm{ml}^{-1}\right)\right)$} \\
\hline & $91 / 293$ & $\begin{array}{c}1.98(1.50,2.60) \\
\chi^{2}=24.6(P<0.001)\end{array}$ & $\begin{array}{c}1.75(1.31,2.32) \\
\chi^{2}=15.2(P<0.0001)\end{array}$ \\
\hline \multicolumn{4}{|c|}{ Ki-67 groups (\%) } \\
\hline $\begin{array}{l}\leqslant 10 \\
>10\end{array}$ & $\begin{array}{c}81 / 277 \\
10 / 16\end{array}$ & $\begin{array}{c}1 \text { (ref) } \\
3.42(1.76,6.62) \\
\chi^{2}=9.8(P=0.002)\end{array}$ & $\begin{array}{c}1(\text { ref }) \\
2.66(1.36,5.19) \\
\chi^{2}=6.5(P=0.011)\end{array}$ \\
\hline \multicolumn{4}{|c|}{ Extent of disease $(\%)^{b}$} \\
\hline $\begin{array}{l}<50 \\
\geqslant 50 \text { to }<100 \\
100\end{array}$ & $\begin{array}{c}11 / 50 \\
22 / 86 \\
53 / 130\end{array}$ & $\begin{array}{c}1.00 \\
1.49(0.72,3.07) \\
2.42(1.26,4.65) \\
\chi^{2}=9.6(P=0.002)\end{array}$ & \\
\hline \multicolumn{4}{|c|}{ Age at diagnosis (years) } \\
\hline & $91 / 293$ & $\begin{array}{c}1.05(1.00,1.10) \\
\chi^{2}=4.3(P=0.039)\end{array}$ & \\
\hline \multicolumn{4}{|c|}{ 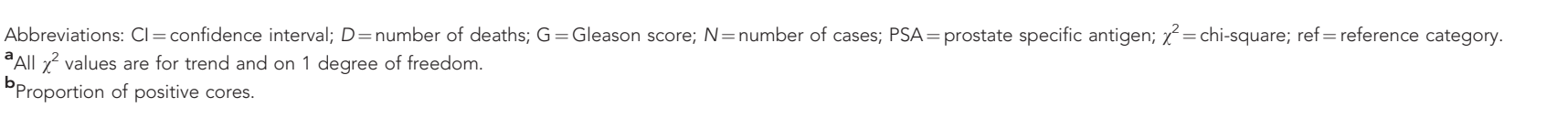 } \\
\hline
\end{tabular}

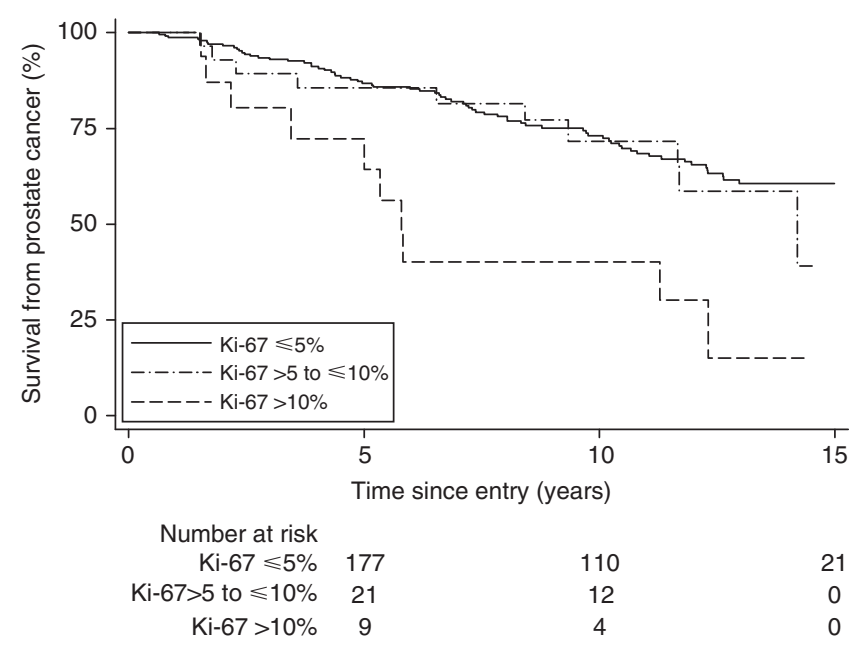

Figure 4. Kaplan-Meier estimates of prostate cancer death according to Ki-67 score in three groups: different categories of Ki-67 score are shown by different lines: solid, $\leqslant 5 \%$; dotted, $>5$ to $\leqslant 10 \%$; dashed, $>10 \%$.

heterogeneous disease and sampling the various regions of cancer is important. This is routinely performed in studies examining RP specimens. The TURP specimens examined in our previous study allowed three tumour foci to be sampled in the vast majority of cases, thus allowing $\mathrm{Ki}-67$ assessment in multiple regions of tumour. However, needle biopsies sample much less of the prostate cancer than TURP specimens and there were $<100$ tumour cells in some biopsies. Also, because the biopsies were performed before

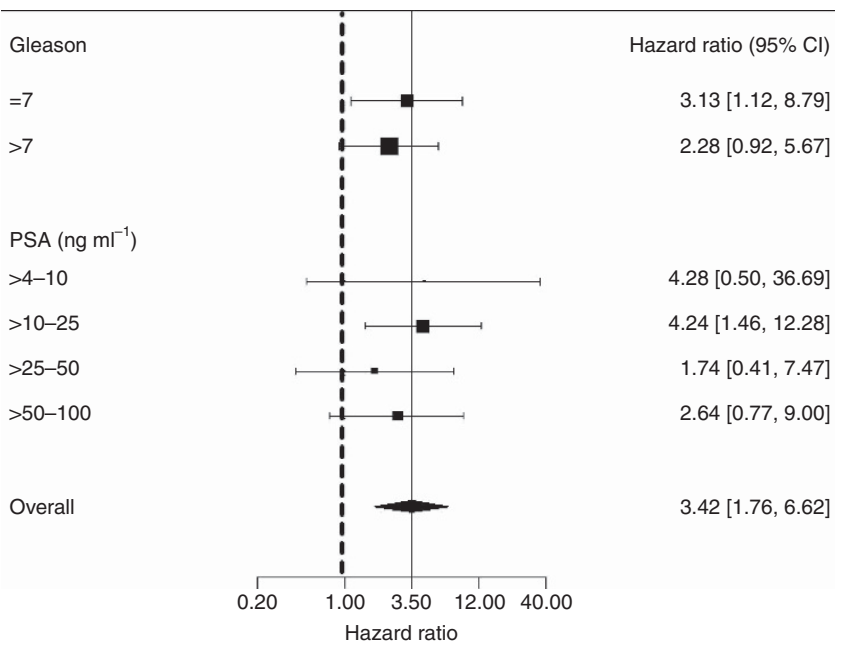

Figure 5. Hazard ratio for prostate cancer mortality for Ki-67 score ( $\leqslant 10 \%,>10 \%$ ) within different clinical subgroups of Gleason score and prostate-specific antigen (PSA). The area of the box is proportional to the amount of information available and the horizontal bars represent $95 \%$ confidence intervals. The lowest Gleason group $(<7)$ and PSA group $\left(\leqslant 4 \mathrm{ng} \mathrm{ml}^{-1}\right.$ ) were omitted because there was only one observation in each of these groups.

1997, most of the cohort consisted of only between one and four cores per patient and very few had sextant prostatic sampling. This is therefore a limited sample including far fewer biopsies than the now minimum recommended guidelines for prostate cancer biopsy, leading to an inevitable lack of tissue. Better results may 
be achievable with modern diagnostic methods and current guidelines, where 12 or more cores are taken that would be more indicative of the overall cancer burden and the most aggressive focus of tumour is more likely to be sampled.

There are a number of issues that need to be considered before recommending routine Ki-67 assessment of diagnostic specimens. As with all IHC assays, there is considerable potential for variation in Ki-67 IHC staining. Many of these points have been discussed within the breast cancer context (Dowsett et al, 2011). Variations in ischaemic time or formalin fixation may affect the amount of Ki-67 staining seen in prostate tissue similar to many other IHC assessments (Havelund et al, 2012). However, in this study, as Ki-67 IHC staining has been performed on biopsy samples of uniform thickness, formalin fixation occurs in a relatively controlled fashion and there is minimal ischaemic time. This is more of a problem in RP specimens where penetration of formalin may vary throughout the specimen.

Speed of processing the sample into wax embedded blocks also may influence immunostaining. Samples used in this study were collected from UK pathology laboratories, where samples taken to diagnose cancer are normally processed promptly and not left in formalin for longer than $48 \mathrm{~h}$. However, this is an assumption.

Immunohistochemical staining can vary from run to run. In this study, we were able to assay the total cohort for Ki-67 using TMAs and fewer runs were needed than to stain each individual core. However, if $\mathrm{Ki}-67 \mathrm{IHC}$ staining is to be used on a routine basis, this would not be possible. Variations in techniques are undoubtedly important (Fasanella et al, 2002) and a consensus similar to that recently achieved in breast cancer will be necessary if the technique is to move into the clinical sphere (Dowsett et al, 2011, Mengel et al, 2011).

In addition, this study has not dealt with the issue of interobserver variation, which is significant in many pathological data: even including well-accepted pathological assessments such as Gleason score. The fact that Ki-67 assessment is robust in so many studies suggests that, similar to Gleason score, it will be robust when applied clinically.

Here, we scored Ki-67 in a semiquantitative manner, easily applicable in a routine pathology laboratory. We did not use computer-based systems as compared with other solid cancers, prostatic cancer is very difficult to identify by these methods. This is due to the subtle nature of the pleomorphism seen in prostatic cancers compared with normal glands, and the frequent intermingling of benign and malignant glands, as well as the presence of abundant stroma in many cases. The tiny nature of these samples would have made this an even greater challenge. Our group has previously reported both quantitative and semiquantitative methods to assess Ki-67 positivity (Berney et al, 2009). As the simpler method proved as informative as the more laborious quantitative methodology, it was used in this series. It is also more likely to be adopted in routine practice.

The stepwise scoring system provided several distinct values that could be implemented as cutoff points and in this needle biopsy cohort, a $10 \%$ cutoff was found to provide useful additional prognostic information to that provided by Gleason score and PSA. The Ki-67 dichotomous variable with a 10\% cutoff was more prognostic for prostate cancer death than the 5\% cutoff reported in our previous TURP cohort and matches the $10 \%$ cutoff reported in a needle biopsy cohort by Zellweger et al (2009), for biochemical recurrence.

Commercial tests that utilise morphology, immunochemistry of prostate adenocarcinoma biomarkers, or RNA analysis are in development, but are much more technically demanding. One such test (CCP score) has recently been shown to be highly predictive of mortality in TURP and needle biopsy cohorts and in a RP cohort (where prediction of biochemical recurrence was also observed) (Cuzick et al, 2011, 2012). While IHC measurement of Ki-67 was substantially less predictive than the mRNA-based CCP score, it may have a role in instances where the CCP score is not feasible or affordable.

Future studies will include the assessment of intra-observer variation, and the utilisation of a larger and more contemporaneous series of conservatively treated prostate cancers.

\section{ACKNOWLEDGEMENTS}

We gratefully acknowledge support from Cancer Research UK, The Orchid Appeal, National Institutes of Health (SPORE) and the Koch Foundation. We also thank investigators and staff in the cancer registries and participating hospitals (Online Supplementary material, Appendix) for their support.

\section{REFERENCES}

Berney DM, Gopalan A, Kudahetti S, Fisher G, Ambroisine L, Foster CS Reuter V, Eastham J, Moller H, Kattan MW, Gerald W, Cooper C, Scardino P, Cuzick J (2009) Ki-67 and outcome in clinically localised prostate cancer: analysis of conservatively treated prostate cancer patients from the Trans-Atlantic Prostate Group study. Br J Cancer 100(6): 888-893.

Cowen D, Troncoso P, Khoo VS, Zagars GK, von Eschenbach AC, Meistrich ML, Pollack A (2002) Ki-67 staining is an independent correlate of biochemical failure in prostate cancer treated with radiotherapy. Clin Cancer Res 8(5): 1148-1154.

Cuzick J, Berney DM, Fisher G, Mesher D, Møller H, Reid JE, Perry M, Park J, Younus A, Gutin A, Foster CS, Scardino P, Lanchbury JS, Stone S. on behalf of the Transatlantic Prostate Group (2012) Prognostic value of a cell cycle progression signature for prostate cancer death in a conservatively managed needle biopsy cohort. Br J Cancer 106: 1095-1099.

Cuzick J, Fisher G, Kattan MW, Berney D, Oliver T, Foster CS, Møller H, Reuter V, Fearn P, Eastham J, Scardino P. Transatlantic Prostate Group (2006) Long-term outcome among men with conservatively treated localised prostate cancer. Br J Cancer 95: 1186-1194.

Cuzick J, Swanson GP, Fisher G, Brothman AR, Berney DM, Reid JE, Mesher D, Speights VO, Stankiewicz E, Foster CS, Møller H, Scardino P, Warren JD, Park J, Younus A, Flake 2nd DD, Wagner S, Gutin A, Lanchbury JS, Stone S. Transatlantic Prostate Group (2011) Prognostic value of an RNA expression signature derived from cell cycle proliferation genes in patients with prostate cancer: a retrospective study. Lancet Oncol 12(3): 245-255.

D’Amico AV, Halabi S, Vollmer R, Loffredo M, McMahon E, Sanford B, Archer L, Vogelzang NJ, Small EJ, Kantoff PW (2008) p53 protein expression status and recurrence in men treated with radiation and androgen suppression therapy for higher-risk prostate cancer: a prospective phase II Cancer and Leukemia Group B Study (CALGB 9682). Urology 71: 933-937.

Dowsett M, Nielsen TO, A'Hern R, Bartlett J, Coombes RC, Cuzick J, Ellis M, Henry NL, Hugh JC, Lively T, McShane L, Paik S, Penault-Llorca F, Prudkin L, Regan M, Salter J, Sotiriou C, Smith IE, Viale G, Zujewski JA, Hayes DF. International Ki-67 in Breast Cancer Working Group (2011) Assessment of Ki67 in breast cancer: recommendations from the International Ki67 in Breast Cancer working group. J Natl Cancer Inst 103(22): 1656-1664.

Epstein JI, Allsbrook Jr WC, Amin MB, Egevad LL. ISUP Grading Committee (2005) The 2005 International Society of Urological Pathology (ISUP) Consensus Conference on Gleason Grading of Prostatic Carcinoma. Am J Surg Pathol 29(9): 1228-1242.

Etzioni R, Penson DF, Legler JM, di Tommaso D, Boer R, Gann PH, Feuer EJ (2002) Overdiagnosis due to prostate-specific antigen screening: lessons from U.S. prostate cancer incidence trends. J Natl Cancer Inst 94(13): 981-990.

Fasanella S, Leonardi E, Cantaloni C, Eccher C, Bazzanella I, Aldovini D, Bragantini E, Morelli L, Cuorvo LV, Ferro A, Gasperetti F, Berlanda G, Dalla Palma P, Barbareschi M (2002) Proliferative activity in human breast cancer: Ki-67 automated evaluation and the influence of different Ki-67 equivalent antibodies. J Pathol 198(3): 292-299.

Gunia S, Albrecht K, Koch S, Herrmann T, Ecke T, Loy V, Linke J, Siegsmund M, May M (2008) Ki67 staining index and neuroendocrine differentiation 
aggravate adverse prognostic parameters in prostate cancer and are characterized by negligible inter-observer variability. World J Urol 26(3): 243-250.

Havelund BM, Olsen DA, Andersen RF, Spindler KL, Brandslund I, Jakobsen A, Soerensen FB (2012) The influence of tissue ischemia on biomarker expression in colorectal cancer. Appl Immunohistochem Mol Morphol; e-pub ahead of print 10 October 2012.

Jhavar S, Bartlett J, Kovacs G, Corbishley C, Dearnaley D, Eeles R, Khoo V, Huddart R, Horwich A, Thompson A, Norman A, Brewer D, Cooper CS, Parker C (2009) Biopsy tissue microarray study of Ki-67 expression in untreated, localized prostate cancer managed by active surveillance. Prostate Cancer Prostatic Dis 12(2): 143-147.

Khor LY, Bae K, Paulus R, Al-Saleem T, Hammond ME, Grignon DJ, Che M, Venkatesan V, Byhardt RW, Rotman M, Hanks GE, Sandler HM, Pollack A (2009) MDM2 and Ki-67 predict for distant metastasis and mortality in men treated with radiotherapy and androgen deprivation for prostate cancer: RTOG 92-02. J Clin Oncol 27(19): 3177-3184.

Kristiansen G (2012) Diagnostic and prognostic molecular biomarkers for prostate cancer. Histopathology 60(1): 125-141.

Laitinen S, Martikainen PM, Tolonen T, Isola J, Tammela TL, Visakorpi T (2008) EZH2, Ki-67 and MCM7 are prognostic markers in prostatectomy treated patients. Int J Cancer 122(3): 595-602.

Li R, Heydon K, Hammond ME, Grignon DJ, Roach 3rd M, Wolkov HB, Sandler HM, Shipley WU, Pollack A (2004) Ki-67 staining index predicts distant metastasis and survival in locally advanced prostate cancer treated with radiotherapy: an analysis of patients in radiation therapy oncology group protocol 86-10. Clin Cancer Res 10(12 Pt 1): 4118-4124.

Lophatananon A, Tyndale-Biscoe S, Malcolm E, Rippon HJ, Holmes K, Firkins LA, Fenton M, Crowe S, Stewart-Brown S, Gnanapragasam VJ, Muir KR (2011) The James Lind Alliance approach to priority setting for prostate cancer research: an integrative methodology based on patient and clinician participation. BJU Int 108: 1040-1043.

McCarthy F, Dennis N, Flohr P, Jhavar S, Parker C, Cooper CS (2011) Highdensity tissue microarrays from prostate needle biopsies. J Clin Pathol 64 88-90.

Mengel M, von Wasielewski R, Wiese B, Rüdiger T, Müller-Hermelink HK, Kreipe $H$ (2011) Inter-laboratory and inter-observer reproducibility of immunohistochemical assessment of the Ki-67 labelling index in a large multi-centre trial. Diagn Pathol 6(Suppl 1): S7.

Pollack A, Cowen D, Troncoso P, Zagars GK, von Eschenbach AC, Meistrich ML, McDonnell T (2003) Molecular markers of outcome after radiotherapy in patients with prostate carcinoma: Ki-67, bcl-2, bax, and bcl-x. Cancer 97(7): 1630-1638.
Pollack A, DeSilvio M, Khor LY, Li R, Al-Saleem TI, Hammond ME, Venkatesan V, Lawton CA, Roach 3rd M, Shipley WU, Hanks GE, Sandler HM (2004) Ki-67 staining is a strong predictor of distant metastasis and mortality for men with prostate cancer treated with radiotherapy plus androgen deprivation: Radiation Therapy Oncology Group Trial 92-02. J Clin Oncol 22(11): 2133-2140.

Rubin MA, Dunn R, Strawderman M, Pienta KJ (2002) Tissue microarray sampling strategy for prostate cancer biomarker analysis. Am J Surg Pathol 26(3): 312-319.

Rubio J, Ramos D, López-Guerrero JA, Iborra I, Collado A, Solsona E, Almenar S, Llombart-Bosch A (2005) Immunohistochemical expression of Ki-67 antigen, cox- 2 and $\mathrm{Bax} / \mathrm{Bcl}-2$ in prostate cancer; prognostic value in biopsies and radical prostatectomy specimens. Eur Urol 48(5): $745-751$.

Sebo TJ, Cheville JC, Riehle DL, Lohse CM, Pankratz VS, Myers RP, Blute ML, Zincke H (2002) Perineural invasion and MIB-1 positivity in addition to Gleason score are significant preoperative predictors of progression after radical retropubic prostatectomy for prostate cancer. Am J Surg Pathol 26(4): 431-439.

Stattin P, Damber JE, Karlberg L, Bergh A (1997) Cell proliferation assessed by Ki-67 immunoreactivity on formalin fixed tissues is a predictive factor for survival in prostate cancer. J Urol 157(1): 219-222.

Vergis R, Corbishley CM, Thomas K, Horwich A, Huddart R, Khoo V, Eeles R, Sydes MR, Cooper CS, Dearnaley D, Parker C (2010) Expression of Bcl2 , p53, and MDM2 in localized prostate cancer with respect to the outcome of radical radiotherapy dose escalation. Int J Radiat Oncol Biol Phys 78: 35-41.

WHO. International Statistical Classification of Diseases and Related Health Problems. 10th revision, 4th edition (2010) ISBN 9789241548342 http:// www.who.int/classifications/icd/ICD10Volume2_en_2010.pdf.

Zellweger T, Günther S, Zlobec I, Savic S, Sauter G, Moch H, Mattarelli G, Eichenberger T, Curschellas E, Rüfenacht H, Bachmann A, Gasser TC, Mihatsch MJ, Bubendorf L (2009) Tumour growth fraction measured by immunohistochemical staining of Ki67 is an independent prognostic factor in preoperative prostate biopsies with small-volume or low-grade prostate cancer. Int J Cancer 124(9): 2116-2123.

This work is published under the standard license to publish agreement. After 12 months the work will become freely available and the license terms will switch to a Creative Commons AttributionNonCommercial-Share Alike 3.0 Unported License.

Supplementary Information accompanies this paper on British Journal of Cancer website (http://www.nature.com/bjc) 